\title{
Eleição das equipes diretivas das escolas públicas: os limites e as possibilidades da eleição de diretores
}

\begin{abstract}
Resumo
Considerando a importância e a exigência legal de ser a Gestão Democrática a atual configuração da gestão escolar, faz-se necessário entender melhor esta forma de administrar. No decorrer da história, as práticas autoritárias comandavam as escolas, e hoje a democracia garante, ou deveria garantir, voz e vez para todos. Este artigo apresenta um estudo sobre a gestão democrática das escolas públicas estaduais, no Rio Grande do Sul, focado principalmente na eleição das equipes diretivas. Tem o objetivo de conhecer e aprofundar como ocorre o processo eletivo, analisando os avanços e os limites evidenciados na atualidade. O conteúdo fundamenta-se em referencial teórico atentamente analisado, que instiga reflexões acerca da Gestão Democrática e, mais especificamente, do processo de eleição de diretores. Busca elementos práticos na pesquisa de campo, realizada em escolas estaduais, no município de Parobé, e permite a construção de significados que possam auxiliar na compreensão e evolução do processo enquanto manifestação da democracia no ambiente escolar.
\end{abstract}

Palavras-chave: Gestão democrática. Eleição de diretores. Escola.

\begin{abstract}
Considering the importance and legal requirement of being a Democratic administration the current setting of school management, it is necessary to better understand how to manage this. Throughout history, the authoritarian practices commanded the schools and now democracy ensures, or should ensure, voice, and once for all. This article presents a study on the democratic management of public schools in Rio Grande do Sul, mainly focused on the election of the management teams. Aims to meet and deepen as the election process occurs by analyzing the advances and limitations evident today. The content is based on the theoretical framework carefully analyzed, which instigates reflections on the Democratic Management and, more specifically, the process of election of directors. Search practical elements in field research conducted in public schools in the municipality of Parobé and allows the construction of meanings that can help them understand the process and evolution as a manifestation of democracy at school.
\end{abstract}

Keywords: Democratic administration. Election of directors. School.

\footnotetext{
${ }^{1}$ Professora da Rede Pública Estadual e Municipal no Município de Parobé (RS). Especialista em Gestão Educacional. catibattisti@gmail.com

2 Professora das Faculdades Integradas de Taquara - RS (FACCAT). Doutora em Educação. rcaetano@faccat.br
} 


\section{Introdução}

A gestão da escola pública pode ser entendida como uma maneira de organizar o funcionamento da escola quanto aos aspectos administrativos, pedagógicos e financeiros. Quando esta gestão se diz democrática, deve proporcionar uma dinâmica que visa garantir processos coletivos, não apenas de participação, mas também de decisão.

Ao pensar a gestão democrática, além de observá-la sob a ótica da participação, é preciso identificá-la pela descentralização do poder e pela transparência, com princípios de coletividade.

Esta forma de gerir começou a ganhar atenção a partir de 1988, com a chamada “Constituição Cidadã". Em seu artigo 206, a Constituição Federal (BRASIL, 2014) estabelece os "princípios do ensino", incluindo, entre eles, no Inciso VI, a "gestão democrática do ensino público". Para Gadotti (2014), a gestão democrática não é só um princípio pedagógico, é também um preceito constitucional.

A eleição de diretores é parte do processo de gestão democrática, sendo este o mecanismo utilizado pelas escolas públicas estaduais no Estado do Rio Grande do Sul.

A vinculação do processo eleitoral à gestão democrática é algo indiscutível, mas até que ponto esse processo se apresenta como uma proposta democrática de fato, em que há garantia da participação e do envolvimento dos sujeitos?

Há de se considerar que a democratização da gestão escolar é ainda muito recente. Datam da década de 80 as primeiras conquistas no Estado, as quais resultaram na aprovação da Lei no 8.025/85, que definia a eleição de diretores através de lista tríplice. De lá para cá, muito se avançou. Hoje, a indicação da equipe diretiva é feita pela comunidade escolar; no entanto, práticas de autoritarismo e favorecimento continuam a persistir. Apesar de não ser mais possível admitir a indicação dos diretores, para satisfazer interesses político-partidários, o processo de eleição na escola é, muitas vezes, constrangedor, pois retrata exatamente o mesmo comportamento que se observa na sociedade durante um processo eleitoral, ou seja, clientelismo. Tem-se dificuldade de compreender que o espaço da escola, que deveria dar exemplo de discernimento e cidadania, ainda está caminhando a passos lentos nesse processo.

Contudo, a oportunidade de escolher os diretores e vice-diretores constitui, sem dúvida, uma conquista, sendo um dos aspectos que influencia intensamente na gestão da escola.

A pesquisa apresentada pretende levantar e produzir elementos teóricos e práticos que permitam avançar na efetivação da eleição de diretores como movimento real da democratização do ensino. Visa à compreensão do processo eleitoral das equipes diretivas nas escolas públicas da rede estadual no município de Parobé. A pesquisa se propõe a identificar os significados do processo, entendendo, interpretando e aprofundando os elementos abordados.

A metodologia utilizada baseia-se na pesquisa qualitativo-descritiva, trazendo uma análise bibliográfica e o levantamento de dados através de questionários, realizados em duas instituições estaduais de ensino, com professores, funcionários e gestores, no município de Parobé.

Primeiramente, realizou-se uma investigação bibliográfica para buscar conhe- 
cimentos científicos especializados sobre o assunto. Através da leitura cuidadosa dos autores e obras selecionados, as informações foram analisadas, embasando o conhecimento necessário ao estudo do problema a ser pesquisado. A análise documental dos planos de ação de três equipes candidatas à direção de escola permitiu um comparativo de intenções, bem como a verificação da estrutura dos projetos.

Num segundo momento, foi realizada uma pesquisa de campo, com uma amostragem de professores, funcionários e membros de equipes que se candidataram à direção de escola. Nesta etapa, 20 (vinte) pessoas contribuíram com o estudo.

A partir da coleta de dados, o objetivo da pesquisa foi compreender como se dá o surgimento das equipes candidatas à direção das escolas públicas estaduais; o que pretendem estas equipes em seus projetos de gestão e de que forma a comunidade escolar é informada de tais projetos; como acontece o envolvimento de pais, alunos, professores e funcionários no processo eleitoral; quais são os mecanismos utilizados na articulação da campanha eleitoral. Os dados foram organizados, tabulados e interpretados à luz do referencial teórico estudado.

A educação, como instrumento de transformação da sociedade, tem a finalidade de fornecer as ferramentas necessárias para que os sujeitos atuem criticamente no meio em que vivem. A partir dessa concepção de educação, e pensando que todas as pessoas que fazem parte do universo escolar são sujeitos desse espaço, a pesquisa realizada é uma contribuição para a transformação da gestão escolar.

\section{Gestão democrática}

Gerir democraticamente uma escola! Este é um assunto que tem sido amplamente estudado e discutido por inúmeros autores. Trata-se de um processo complexo, que implica uma transformação na prática das pessoas. Segundo Vasconcellos (2009, p. 51): "[...] o movimento pela democratização da educação é um amplo e complexo processo, que tem como meta a mudança da prática em sala de aula e na escola".

A origem do movimento de gestão democrática da escola pública no Brasil se deu por volta de 1970, com a mobilização da classe trabalhadora, que reivindicava o direito de seus filhos à escola pública, entre outros fatores. Associados a essa mobilização, os profissionais da educação começaram a se organizar, enquanto sindicato, e alcançaram algumas conquistas. Sobre estas mobilizações, Amaral (2011, p. 16) coloca:

É neste contexto que surge a expressão 'gestão democrática da educação'. Esta forma de gestão é sustentada por mecanismos, como o processo de eleição para diretor, a constituição e funcionamento de Conselhos Escolares, mecanismos estes para a autonomia administrativa, ao que se soma a reivindicação de autonomia financeira e pedagógica escolar.

A experiência democrática no Brasil é ainda muito recente, e é neste contexto que a escola está inserida, sofrendo os reflexos desta realidade. O autoritarismo ainda está impregnado nas relações sociais. Conforme Paro (2005, p. 19): “[...] uma sociedade autoritária, com tradição autoritária, com organização autoritária e, não por acaso, articulada com interesses autoritários de uma minoria, orienta-se na direção oposta à da democracia". 
Mas, a partir da década de 1980, tem se verificado uma tendência de democratização da escola pública, acompanhando, em certa medida, a democratização da sociedade. Essa democratização vem ocorrendo através de medidas, como as relacionadas aos mecanismos de participação (conselhos, associação de pais e mestres, grêmio estudantil) à eleição de diretores e a iniciativas que estimulam o envolvimento da comunidade escolar.

Mesmo com os avanços da democratização, por vezes, na escola pública, ainda perpassam práticas autoritárias. Existem direções que se dizem democráticas, porque permitem que as pessoas participem de algumas decisões; porém, se a participação depende da permissão de alguém, não se trata de democracia, pois, de acordo com Paro (2005, p. 19): "democracia não se concede, se realiza".

Alcançar, de fato, a democratização do ensino tem como pressuposto inicial a participação de todos os envolvidos no processo educacional; assim, a cooperação entre pais, alunos, professores e funcionários é fundamental. No entanto, no Brasil, não se tem uma cultura de participação: muitas vezes, a escola não tem interesse em que haja esta participação. Demo (1985, p. 3) é bastante crítico ao dizer: "[...] qualquer instituição aprecia participação, desde que não atrapalhe".

Ainda, encontram-se fatores ligados às condições de trabalho e de vida da população que fazem com que ela não encontre caminhos para se envolver com a escola. Também a recíproca é verdadeira: a escola pouco se envolve com os problemas da comunidade.

Ao mencionar que "[...] a participação da comunidade na escola é um caminho que se faz ao caminhar", Paro $(2005$, p. 17) deixa claro que a participação é um processo e, como tal, é prolongado e contínuo, no qual é preciso acreditar firmemente para não desistir diante das primeiras dificuldades.

Demo (1985, p. 3) também fala sobre a participação, considerando-a possível e necessária, mas alerta: "Participação está sempre a um passo da farsa. Porquanto, sendo o contrário da dominação, a ideologia mais interessante e envolvente desta é a máscara da participação".

O autor ainda chama a atenção para as questões de moda e modismo, pois, se os termos ligados à participação não aparecerem no planejamento, avaliação, pesquisa, entre outros, levanta a suspeita de má intenção, despreparo ou desatualização. Faz-se necessário ter melhor compreensão dos elementos de participação, pois, muitas vezes, não há coerência entre o que se declara e o que ocorre na prática.

Gadotti (2014) estabelece uma relação entre participação e democracia, esclarecendo que a participação não só define a qualidade da democracia como a forma de viver a democracia.

A gestão democrática do ensino público teve início nos movimentos que lutavam pela democratização do país, que incluíam a democratização da gestão e da educação. Com a Constituição Federal de 1988, esses princípios foram incorporados também nas Constituições Estaduais e nas Leis Orgânicas dos municípios. Cabe, porém, bem lembrar o que diz Demo (1985, p. 6): “[...] não há processo participativo autêntico por atacado, por decreto". Portanto, apenas a legislação não basta, mas, ao procurar atender ao princípio constitucional, a escola busca se transformar e reorganizar a gestão. 
Ao que dispõe a Lei no 10.576/95, atualizada pela Lei no 13.990/2012, do Estado do Rio Grande do Sul (1995), garante-se:

Art. 1ํ - A gestão democrática do ensino público, princípio inscrito no artigo 206, inciso VI da Constituição Federal e no artigo 197, inciso VI da Constituição do Estado, será exercida na forma desta lei, com vista à observância dos seguintes preceitos:

I - autonomia dos estabelecimentos de ensino na gestão administrativa, financeira e pedagógica;

II - livre organização dos segmentos da comunidade escolar;

III - participação dos segmentos da comunidade escolar nos processos decisórios em órgãos colegiados;

IV - transparência dos mecanismos administrativos, financeiros e pedagógicos;

V - garantia da descentralização do processo educacional;

VI - valorização dos profissionais da educação;

VII - eficiência no uso dos recursos.

Art. 2ㅇ - Os estabelecimentos de ensino serão instituídos como órgãos relativamente autônomos, dotados de autonomia na gestão administrativa, financeira e pedagógica, em consonância com a legislação específica de cada setor.

Art. 3o - Todo estabelecimento de ensino está sujeito à supervisão do Governador e do Secretário de Estado da Educação, na forma prevista para as entidades da Administração Indireta.

Seguindo os preceitos da lei, considera-se que a gestão democrática se contrapõe à burocracia e ao autoritarismo da administração escolar e mesmo do Estado, socializando o poder, incentivando a participação da comunidade e oferecendo autonomia.

Ao abordar a gestão democrática do ensino público estadual no Rio Grande do Sul, é necessário considerar a relação entre o Centro de Professores do Estado do Rio Grande do Sul - CPERS (2014) - que é formado também por funcionários das escolas públicas - e os governos estaduais.

Com o processo de redemocratização do país, na década de 80 , os profissionais da educação discutiam sobre o desejo de uma educação democrática, com objetivos de universalização. De acordo com Amaral (2011, p. 106): “[...] como exemplo de movimento social que se mobilizou para a democratização da educação no Rio Grande do Sul, temos o CPERS sindicato".

Segundo o histórico do sindicato, a entidade tem registros à frente de várias lutas em defesa dos direitos dos profissionais da educação e em defesa da democracia. Consta que, em 1985, após sessenta dias de greve, foi assegurada a eleição para diretores de escola, entre outras conquistas. Conforme Amaral (2011, p. 105): "A década de 1980 mostrou-se decisiva para a construção e a efetivação da democracia, diante de um quadro em que o governo estadual não cumpria suas promessas de campanha, o CPERS pressionou com a declaração de greve".

Após a greve, que resultou na aprovação da Lei no 8.025, que dispunha sobre a eleição para diretor, e da Lei 8.026, que tratava das vantagens do Magistério Público Estadual, iniciou-se o processo que normatizava a gestão democrática no Rio Grande do Sul. 


\section{Eleição de diretores}

A eleição dos dirigentes escolares é um instrumento para o exercício democrático, que por si só não garante a democratização da gestão, mas é um importante passo neste sentido.

Em relação à escolha dos diretores, a eleição direta é uma das modalidades possíveis, mas outras, como a indicação pelo poder público, a indicação através de lista tríplice ou concurso para diretor também são bastante usuais.

Desde o início da década de 1980 até os dias atuais, a eleição de diretores vem se expandindo nos sistemas de ensino. Isso se deve às reivindicações das escolas e das comunidades, que sabem da importância do diretor na tomada de decisões, então não mais aceitam que este seja nomeado pelo poder público e defenda apenas os interesses do governo. O concurso público para diretor é uma alternativa burocrática que não leva em conta os interesses de cada escola.

O processo de eleição de diretores é bastante variado nos municípios e estados que utilizam essa modalidade. Há variação acerca de quem vota e do peso do voto para os diferentes segmentos da comunidade escolar. Sobre a eleição de diretores, o Programa Nacional de Fortalecimento dos Conselhos Escolares apresenta (BRASIL, 2014, p. 39):

As eleições diretas para diretores, historicamente, tem sido uma das modalidades tidas como das mais democráticas, apesar de ser também uma forma polêmica. A defesa dessa modalidade vincula-se à crença de que o processo implica na retomada ou conquista da decisão sobre os destinos da escola pela própria escola.

Paro (2003, p. 95) também apresenta argumentos para a implantação da eleição de diretores: "[...] fundamenta-se na crença na capacidade da eleição de neutralizar as práticas tradicionalistas calçadas no clientelismo e no favorecimento pessoal". Mas alerta: "[...] isso não significa que o clientelismo tenha deixado de exercer suas influências na escola".

Há muitas expectativas dos sujeitos envolvidos com a eleição de diretores escolares, muitas delas impossíveis de serem realizadas. Segundo Paro (2006, p. 43): “É preciso estar atento para evitar expectativas descabidas que trarão frustrações que podem comprometer a própria crença nas virtudes da eleição".

Paro (2006) ainda coloca que controlar as ações do diretor é uma expectativa que motiva muitos professores a lutarem pelas eleições, e tal expectativa merece um exame detalhado; outra expectativa muito forte é a de superar o autoritarismo e a hierarquia na escola.

De acordo com Dourado (2006, p. 85): “[...] embora as eleições se apresentem como um legítimo canal na luta pela democratização da escola, é necessário não perdermos de vista as limitações do sistema representativo numa sociedade de classes". 
Dourado (2006, p. 85) ainda diz que:

É fundamental ampliarmos os horizontes da democratização da gestão, enfatizando, conjuntamente, a forma de escolha e o exercício da função. Assim a forma de provimento do cargo não pode definir o tipo de gestão, mas certamente, interfere no curso desta. Nesse contexto, visualizar a eleição como ação terminal é incorrer no equívoco de se negar o caráter histórico do processo, pois a eleição deve ser vislumbrada como um instrumento a ser associado a outros na luta pela democratização possível das relações escolares.

Sobre a eleição como garantia da democratização, Paro (2014, p. 67) também alerta: "O envolvimento das pessoas como sujeitos na condução das ações é apenas uma possibilidade, não uma garantia". A eleição é um importante mecanismo no processo de gestão democrática, mas não é o suficiente para garanti-la.

Amaral (2011, p. 152) deixa claro essa mesma visão, ao dizer:

Os mecanismos que sustentam a gestão democrática no Rio Grande do Sul desvelam aspectos que precisam avançar, pois a eleição para diretor não significa o rompimento com o autoritarismo, o patrimonialismo e o clientelismo. 0 funcionamento do Conselho Escolar não garante a participação real da comunidade escolar e a retirada da política de manipulação e favorecimento. A autonomia, administrativa, pedagógica e financeira, não garante o atendimento às demandas da população. No entanto, a legislação construída foi vista como um importante instrumento indutor de mudanças nas práticas escolares.

A forma de provimento do cargo de diretor não define o tipo de gestão. Escolher um diretor através do voto direto não significa que está assegurada uma gestão democrática, que garanta efetiva participação da comunidade, até mesmo porque não é suficiente criar mecanismos de participação, é necessário criar condições. E, muito embora haja um compromisso com a comunidade, há também um compromisso com o governo.

Contudo, as eleições diretas tem sido a modalidade considerada mais democrática pelos movimentos sociais, pois democracia vincula-se à autonomia e participação, e a proposta da eleição é a que melhor expressa essas características.

Além de ser escolhido pela comunidade escolar, outro fator de fundamental importância para a realização de um bom trabalho democrático, é que o diretor passe por um processo adequado de formação, a fim de buscar conhecimentos específicos sobre gestão.

3.1 A Eleição de Diretores no Sistema Estadual de Ensino do Rio Grande do Sul na atualidade

Segundo a Lei no 10.576 , de 1995, atualizada pela Lei no 13.990 de 2012, que rege a gestão democrática do ensino público no Rio Grande do Sul, uma das principais mudanças ocorridas foi a substituição dos termos "diretor" e "vice-diretor" por "equipe diretiva", integrada pelo diretor, vice-diretor e coordenador pedagógico. Consta na lei que a administração dos estabelecimentos de ensino será feita pela Equipe Diretiva e pelo Conselho Escolar.

Está assegurado que os diretores e vice-diretores serão indicados pela comuni- 
dade escolar de cada estabelecimento de ensino, mediante votação direta, por meio de chapa. Até o ano de 2012, as votações eram apenas para o diretor, que, posteriormente, escolhia sua equipe. Além da indicação pela comunidade escolar, o processo eleitoral também exige que o diretor e o vice-diretor (representante legal) frequentem um curso de gestão escolar de, no mínimo, quarenta horas, fornecido pela Secretaria de Educação do Estado.

O período de mandato da equipe diretiva corresponde a três anos, sendo permitida apenas uma recondução sucessiva. A vacância da função de diretor e/ou de vice-diretor ocorre por conclusão do mandato, renúncia, destituição, aposentadoria ou morte.

Podem concorrer ao cargo de diretor ou vice-diretor de escola os membros do magistério ou servidores públicos em exercício no estabelecimento de ensino. Estes devem integrar-se a uma chapa e cumprir alguns requisitos, dentre eles, destacam-se possuir curso superior na área da educação; ter estabilidade no serviço público; estar no mínimo há três anos em efetivo serviço no magistério público estadual ou serviço público estadual; apresentar um plano de ação para implementar na comunidade, abordando aspectos administrativos, financeiros e pedagógicos; comprometer-se a realizar curso de capacitação em gestão; estar em dia com a justiça eleitoral.

Quanto à formação em nível superior, há exceção para as escolas que oferecem até o quinto ano do ensino fundamental, onde o diretor pode ter apenas nível médio (modalidade normal), e também para as escolas técnicas, onde o diretor pode ter titulação mínima específica de técnico.

O início do processo eleitoral se dá com a constituição de uma Comissão Eleitoral, composta por um ou dois representantes de cada segmento que compõe a comunidade escolar, eleitos em assembleia. Esta comissão tem como incumbência homologar as candidaturas; decidir sobre impugnações; organizar debates públicos para a apresentação dos planos de ação dos candidatos; constituir as mesas eleitorais e escurtinadoras; providenciar todo material necessário ao processo de indicação; definir e divulgar o horário de funcionamento das urnas; comunicar ao Presidente do Conselho Escolar e ao Diretor da escola os resultados do processo eleitoral.

São votantes, neste processo, os alunos matriculados na escola, frequentando a partir do quinto ano ou com no mínimo doze anos, os pais ou responsáveis dos alunos menores de dezoito anos, os membros do magistério e servidores em exercício na escola no dia da votação.

Para ser válida, a votação precisa de, no mínimo, trinta por cento de participação do segmento pais/alunos e de, no mínimo, cinquenta por cento do segmento magistério/servidores. Caso não seja atingida a participação necessária, nova votação é marcada num prazo de oito dias. Se ainda assim não houver a participação necessária, a Secretaria de Educação designará diretor e vice-diretor aqueles que, em exercício na escola, apresentarem maior titulação na área de educação. Na hipótese de não haver professor ou servidor que aceite a designação, a Secretaria de Educação poderá indicar um professor ou servidor de outra escola.

Considerar-se-á indicada para o cargo a chapa que obtiver cinquenta por cento mais um dos votos válidos, não computados os votos brancos e nulos, respeitada a proporcionalidade para os segmentos pais/alunos e magistério/servidores. Na hipótese 
de haver mais de duas chapas, e nenhuma alcançar o percentual exigido, far-se-á nova votação em segundo turno.

Há de se destacar que os candidatos a diretor/vice-diretor apresentam para a comunidade escolar um plano de ação para seu mandato, que tem o intuito de esclarecer a proposta de gestão da equipe, trazendo ao conhecimento de todos os objetivos do mandato, o que farão para alcançá-los e como será realizado o trabalho na escola.

\subsection{Planos de ação como instrumento de gestão}

A elaboração do Plano de Ação da equipe que deseja se candidatar à direção de escola é uma exigência legal. De acordo com o Inciso VI do Art.20 da Lei no 10.577/1995, atualizada até a Lei no 13.990/2012, é requisito para a candidatura: “VI - apresentar plano de ação para implementação na comunidade, abordando, no mínimo, os aspectos administrativos, financeiros e pedagógicos da escola; (Redação dada pela Lei no 13.990/12)".

O Plano de Ação, visando à melhoria da qualidade do desempenho escolar, deve ser entregue à Comissão Eleitoral, no momento da inscrição da equipe, e apresentado para a comunidade escolar, em caráter de debate público, no horário e local estipulado pela Comissão Eleitoral.

O Diário Oficial do Estado do Rio Grande do Sul, na data de onze de setembro de 2012 (p. 82), apresenta a Portaria no 171/2012, que estabelece os elementos para a elaboração do Plano de Ação dos candidatos à direção de escola pública estadual:

A estruturação desse Plano de Ação deve expressar claramente as linhas gerais do projeto pedagógico, com a apresentação das propostas concretas que evidenciem o sentido maior da educação escolar: o compromisso com a aprendizagem de TODOS os alunos. Nesse sentido o Plano deve conter as formas pelas quais a Direção pretende:

a) melhorar a aprendizagem dos alunos utilizando, inclusive, estratégias voltadas à diminuição da reprovação e do abandono da escola;

b) tratar e aperfeiçoar o processo de inclusão, permanência e sucesso dos alunos em geral, mas, em especial daqueles com deficiência e/ou em situação de vulnerabilidade social;

c) estimular a participação e integração da comunidade escolar nas atividades da escola, abrangendo, também, a discussão e definição quanto à aplicação dos recursos da autonomia financeira e outros que o estabelecimento de ensino vier a receber;

d) articular as ações do Conselho Escolar para definir as prioridades relacionadas às questões administrativas, financeiras e pedagógicas, bem como as relacionadas à manutenção e investimentos necessários à qualificação do ambiente escolar e que estejam sob a governabilidade da Direção.

Esses aspectos, entre outros específicos de cada realidade, devem compor o Programa de Gestão, integrando ações com vistas a alcançar o conjunto de objetivos e metas traçados, caracterizando a gestão no período do mandato delegado no processo de indicação da Direção da escola.

Ao analisar os Planos de Ação de três equipes que se candidataram, em 2012, à direção de escolas públicas estaduais, no município de Parobé, é possível constatar que não há um padrão para a elaboração do documento, cada equipe o realiza à sua 
maneira. A estruturação dos planos analisados apresenta objetivos e justificativa, sendo apenas estes os itens em comum.

Os documentos expressam objetivos claros, mas não há clareza de como se pretende atingir tais objetivos. Na medida em que se trata de um plano de ação, parece que faltam justamente as ações que viabilizarão a gestão da equipe. Uma das equipes elaborou uma série de ações, mas classificou-as como objetivos. No corpo dos documentos, há nitidamente um aspecto em comum: o reconhecimento de que um dos principais desafios da escola é garantir a permanência dos alunos no ensino médio.

Quanto ao processo inclusivo, previsto na Portaria no 171 (ESTADO DO RIO GRANDE DO SUL, 2014), não há registro de objetivos e ações relacionadas a esta abordagem. O único apontamento, que aparece em apenas um dos Planos, é o da criação de um processo para abrir uma sala de recursos. A participação da comunidade e o trabalho conjunto com o CPM e o Conselho Escolar estão referidos em todas as propostas.

Diante das observações realizadas nos Planos de Ação estudados, é possível concluir que os aspectos relacionados à participação da comunidade estão bem entendidos como princípio da gestão democrática. Mas, se posteriormente, no cotidiano da escola, esta participação acontece de fato, é outra questão a ser analisada.

Outra significativa interpretação é a de que o compromisso com a aprendizagem de TODOS ainda não encontra o destaque que deveria ter no planejamento da gestão; por vezes, parece esquecido que esta é a finalidade da escola, e que o processo de gestão não precisa estar diretamente relacionado a este fim.

\subsection{Perspectivas dos sujeitos envolvidos no Processo eleitoral}

Ao falar de eleições escolares enquanto processo democrático, percebe-se que as pessoas envolvidas, cada uma a sua maneira, têm compreensão da importância de poder escolher os dirigentes da escola da qual fazem parte.

Há um consenso sobre o entendimento das eleições enquanto manifestação da democracia. Todos os entrevistados afirmam que o processo eleitoral dos dirigentes escolares é de fundamental importância. Uma professora de ensino fundamental menciona a importância do processo como exercício da cidadania. Outra professora diz: "Acho muito importante as eleições escolares, pois é um meio de preparar o aluno, enquanto cidadão, para a escolha de seus futuros governantes".

Tais pensamentos traduzem a ideia de que a escola é um espaço para a participação necessária ao exercício da cidadania, assim como destaca Lakatos (1999), a democracia é o sistema social que sustenta o indivíduo pela sua condição de pessoa, que, independentemente de raça, cor, sexo ou religião, deve participar dos assuntos da comunidade.

A participação é o primeiro passo para consolidar uma democracia capaz de garantir os direitos de todos os cidadãos. A escola deve estar ligada à ideia de liberdade, democracia e cidadania, não pode preparar para a democracia sem que também seja democrática. Seria contraditório ensinar a democracia no meio do autoritarismo.

Quando se analisa o conceito de democracia, no novo dicionário Aurélio (FERREIRA, 2004), que a define como "Doutrina ou regime político baseado nos princípios da 
soberania popular e da distribuição equitativa do poder" e o compara com a opinião dos professores e funcionários sobre as eleições escolares, que as veem como parte do processo democrático, observa-se que há o anseio de que esta democracia realmente aconteça; porém, os profissionais entrevistados apontam valores, tais como ética, respeito, conduta coerente, como requisitos para que as eleições de fato favoreçam a democracia.

Acerca da ética, os Parâmetros Curriculares Nacionais (BRASIL, 1997, p. 49) assim a definem: "Pensamento reflexivo sobre os valores e as normas que regem as condutas humanas". Seria possível existir democracia sem haver ética?

A democracia tem no exercício da ética uma de suas bases, pois aí está o ponto fundamental das relações interpessoais. Portanto, a ética precisa andar junto com a democracia.

É possível perceber, através das opiniões de alguns entrevistados, que políticas sem princípios ainda permeiam a escola, pois foram feitas menções a atos de falsidade e corrupção. Tais afirmações alertam que interesses pessoais e favorecimentos ainda ocorrem durante os processos eleitorais para a indicação de diretores. Paro (1996) fala sobre as eleições escolares, afirmando que o clientelismo não deixa de exercer suas influências, passando, por vezes, a fazer parte do interior da própria escola, tanto durante o processo de eleição, quanto durante o exercício do mandato. As eleições, por si só, não garantem a inexistência de tais atitudes.

De acordo com Amaral (2014), em época de eleição, é comum que políticos prometam favores em troca de votos, façam acusações contra os adversários e promessas de campanha. Mas, e quando os candidatos são educadores e parte dos eleitores, um público que está em formação? Além do péssimo exemplo para os alunos, o fato de reproduzir práticas antiéticas pode provocar um grande mal-estar entre colegas de trabalho. E, diferentemente do que acontece na política, na escola, os vitoriosos e os derrotados precisam trabalhar juntos após as eleições.

Uma pessoa entrevistada destacou a mágoa, por parte dos candidatos, por não receber o voto: "Creio que a eleição é um meio democrático importante, mas, às vezes, algumas pessoas não entendem isso e ficam magoadas quando não recebem o voto". Para Caetano (2014): "As divergências e discussões devem ficar no campo das ideias e não serem entendidas como motivos pessoais". É necessário separar aspectos pessoais de profissionais, mas essa é uma questão que exige maturidade de todos os envolvidos e que muito precisa avançar no ambiente escolar.

O município de Parobé possui cinco escolas estaduais, das quais uma atende apenas ao ensino fundamental, duas atendem aos ensinos fundamental e médio, e duas apenas ao ensino médio. Nas eleições escolares de 2012, destas cinco escolas, quatro tiveram chapa única concorrendo à direção. Em apenas uma escola houve a disputa entre duas chapas.

Há, de acordo com a contribuição dos entrevistados da escola que formou apenas uma chapa, uma concordância prévia entre professores e funcionários. Esta é uma questão a ser analisada, pois a divergência de ideias desacomoda, e essa desacomodação é importante na busca de melhorias. Então é preciso questionar-se se a formação de uma única chapa é por esta estar realmente de acordo com as expectativas, ou se o real motivo é a comodidade. 
É possível observar que a grande maioria daqueles que pretendem assumir funções diretivas acredita que pode fazer algo para melhorar a escola. Em um dos depoimentos, o diretor coloca: "Quis ser diretor pela oportunidade de poder desenvolver um trabalho para melhorar, contribuir, incentivar e formar pessoas de bem". Em apenas uma das entrevistas, aparece um motivo de benefício pessoal, na qual a professora assumiu a função diretiva por necessitar de remoção de cidade.

Feliz constatação perceber que os objetivos de trabalhar por uma educação meIhor aparecem como compromisso pessoal, e que estes objetivos levam as pessoas a se candidatarem à direção de escola. Mesmo porque, status e gratificações não sustentam o peso do trabalho. É preciso ter envolvimento.

Para a formação das equipes candidatas, os critérios que prevalecem são a afinidade e o reconhecimento do bom trabalho desenvolvido pelos colegas. Mas um apontamento importante a ser considerado foi feito por uma professora que se candidatou à vice-direção: "Vários profissionais foram convidados a integrar a equipe por serem competentes, mas não aceitaram, assim acabaram entrando pessoas sem perfil para completar a equipe".

De acordo com os relatos dos profissionais que se candidataram à direção, o Plano de Ação foi elaborado coletivamente pela equipe. Como base para o planejamento, aparecem os critérios de convicções e experiências dos docentes, além da escuta da comunidade escolar em todos os seus segmentos.

Para a articulação da campanha eleitoral, o principal mecanismo utilizado, segundo a pesquisa na escola em que houve a concorrência entre duas chapas, foram as visitas às famílias e a distribuição de panfletos. Na escola em que havia apenas uma chapa, não foi realizada campanha, apenas a apresentação do Plano de Ação para a comunidade.

Amaral (2014) faz importante reflexão acerca das campanhas eleitorais nas escolas, falando sobre os excessos de campanha, que surgem principalmente do receio dos candidatos de não serem lembrados pelos eleitores. Quando um dos pretendentes ao cargo espalha material de propaganda, os outros acham que não terão visibilidade se não agirem da mesma forma. A maneira mais adequada de mobilizar o eleitorado é por meio de conversas e debates.

Ao buscar conhecer quais foram os critérios utilizados para votar em uma ou outra equipe, nas eleições de 2012, os profissionais que atuam na escola em que houve a concorrência de duas chapas apresentaram os seguintes critérios: "Amizade, integridade dos candidatos e melhor proposta de gestão", sendo que este último foi o motivo mais expresso pelos participantes da pesquisa.

Através de depoimentos como: "Escolhi a equipe que apresentou a melhor proposta para toda a comunidade escolar"; "Escolhi a equipe que apresentou uma proposta comprometida com um ensino eficaz"; "Analisei a melhor proposta, que visou promover a educação dentro das condições que a escola oferece", é possível perceber as manifestações de consciência política, em que os indivíduos procuram tomar a melhor decisão dentro de um contexto que, neste caso, é o bem-estar geral da escola.

A consciência política é algo que se constrói na medida em que o tema é abordado, estudado, discutido. Trata-se de uma caminhada que, aos poucos, vai se tornando coletiva. 
A gestão democrática do ensino público no Rio Grande do Sul tem um forte amparo legal no que diz respeito à eleição de diretores, porém isso não garante que o processo seja de fato democrático, traduzindo princípios de participação e excluindo autoritarismos e favorecimentos.

\section{Considerações finais}

O que realmente torna a gestão democrática é a tomada de consciência dos indivíduos, que passam a enxergar o "poder" dos esforços coletivos e a entender a gestão como uma atividade-meio para o fim da educação, que é a aprendizagem de todos os alunos.

Sem dúvida, a eleição de diretores vem ganhando espaço como importante mecanismo para a gestão democrática, trata-se de um passo fundamental para isso. Porém é apenas um passo.

As vantagens de eleger o diretor estão relacionadas ao comprometimento deste com a comunidade que o elegeu. Espera-se que haja maior participação de todos os segmentos na gestão. Mas barreiras, como a reprodução de políticas partidárias, ainda precisam ser quebradas, pois são o caminho contrário do que se espera da escola.

São muitas as possibilidades para que a eleição de diretores se construa enquanto mecanismo de real democracia, porém há muito trabalho pela frente para que esta possa ser observada como uma cultura na escola.

\section{Referências}

AMARAL, Aurélio. Ética nas eleições de diretores, exemplo de cidadania. Disponível em: $<$ http://revistaescola.abril.com.br/gestao-escolar/etica-eleicoes-diretores-exemplo-cidadania-638443.shtml>. Acesso em: 22 ago. 2014.

AMARAL, Josiane Carolina. S. Ramos. A política de gestão de Educação Básica na Rede Estadual de Ensino do Rio Grande do Sul (2007 - 2010). Jundiaí: Paco, 2011.

BRASIL. Constituição Federal de 1988: Art.206. Disponível em: <http://www.jusbrasil. com.br>. Acesso em: 2 abr. 2014.

. Parâmetros Curriculares Nacionais: Temas Transversais. Brasília: MEC/SEF, 1997.

CAETANO, M. R. Reflexões sobre gestão democrática e qualidade de ensino. Disponível em: <file:///C:/Users/Notebook/Downloads/comunicacao_caetano.pdf>. Acesso em: 30 abr. 2014.

CENTRO DE PROFESSORES DO ESTADO DO RIO GRANDE DO SUL. CPERS. 40 Núcleo. Histórico do CPERS Sindicato. Disponível em: <http://nucleo40cpers.blogspot.com.br>. Acesso em: 28 mar. 2014.

DEMO, Pedro. Planejamento Participativo - Visão e revisão. Fórum Educacional, p. 3-22, abr./jun. 1985. 
DOURADO, Luiz F. A escolha de dirigentes escolares: políticas e gestão da educação no Brasil. In: FERREIRA, Naura C. (Org.). Gestão democrática da educação: atuais tendências, novos desafios. 5. ed. São Paulo: Cortez, 2006.

ESTADO DO RIO GRANDE DO SUL. Secretaria da Educação. Lei no 10.576 de 14 de novembro de 1995. Disponível em: <http://www.educacao.rs.gov.br/ dados/lei_10.576_ compilado.pdf>. Acesso em: 21 mar. 2014.

. Portaria no 171 de onze de setembro de 2012. Estabelece os elementos para a elaboração do Plano de Ação dos candidatos à direção de escola pública estadual. Disponível em: <http://www.educacao.rs.gov.br/pse/html/eleicao.jsp? ACAO=acao1>. Acesso em: 17 ago. 2014.

FERREIRA, Aurélio Buarque de Holanda. Novo Dicionário Aurélio da Língua Portuguesa. 3. ed. São Paulo: Positivo, 2004.

GADOTTI, Moacir. Gestão democrática com participação popular. Disponível em: <http://conae2014.mec.gov.br/images/pdf/artigogadotti_final.pdf>. Acesso em: 23 ago. 2014.

LAKATOS, Eva Maria. Sociologia geral. 7. ed. São Paulo: Atlas, 1999.

PARO, Vitor H. Eleição de Diretores de Escolas Públicas: avanços e limites da prática. 1996 Disponível em: <http://rbep.inep.gov.br/index.php/RBEP/article/viewFile/289/291>. Acesso em: 22 mar. 2014.

. Eleição de Diretores: a escola pública experimenta a democracia. 2. ed. São Paulo: Xamã, 2003. . Gestão Democrática da Escola Pública. 3. ed. São Paulo: Ática, 2005. . Gestão Escolar, Democracia e Qualidade do Ensino. São Paulo: Ática, 2006.

VASCONCELLOS, Celso dos S. Coordenação do Trabalho Pedagógico: do Projeto Político Pedagógico ao cotidiano da sala de aula. 12. ed. São Paulo: Libertad, 2009. 